\title{
Innovative Approach in Creation of Integrated Technology of Desalination of Mineralized Water
}

\author{
Inna Trus ${ }^{1 *}$, laroslav Radovenchyk ${ }^{1}$, Vita Halysh ${ }^{1,2}$, Margarita Skiba ${ }^{3}$, \\ Inna Vasylenko ${ }^{3}$, Victoria Vorobyova ${ }^{4}$, Hlushko Olena ${ }^{1}$, Ludmila Sirenko ${ }^{1}$
}

1 Department of Ecology and Technology of Plant Polymers, Faculty of Chemical Engineering, Igor Sikorsky Kyiv Polytechnic Institute, Peremogy Avenu 37/4, 03056 Kyiv, Ukraine

2 Laboratory of Kinetics and Mechanisms of Chemical Transformations on the Surface of Solids, Department of Physico-Chemistry of Carbon Nanomaterials, O.O. Chuiko Institute of Surface Chemistry, National Academy of Sciences of Ukraine, General Naumov St. 17, 03164 Kyiv, Ukraine

3 Department of inorganic substances and Ecology, Faculty of Inorganic Substances, Ukrainian State ChemicalEngineering University, Gagarin Ave. 8, 49005 Dnipro, Ukraine

${ }^{4}$ Department of Physical Chemistry, Faculty of Chemical Technology, National Technical University of Ukraine "Igor Sikorsky Kyiv Polytechnic Institute", Peremogy Avenu 37/4, 03056 Kyiv, Ukraine

* Corresponding author's e-mail: inna.trus.m@gmail.com

\begin{abstract}
In this study, the optimum parameters of membrane desalinization of model solutions were determined and the required efficiency was achieved. Methods for stabilizing treatment of water before barometric desalination were developed to improve the efficiency of membranes. Methods of reagent processing of concentrates after barometric water were proposed to create a low-waste technologies for demineralization of water. It was shown that the precipitate can be used as an additive for cements and a sulfate activator for slag-portland cement.
\end{abstract}

Keywords: membrane, filtering, desalination, reagent precipitation, permeate

\section{INTRODUCTION}

Nowadays, the problem of salinization of water is very common in Ukraine due to natural and anthropogenic factors, and industrial regions suffer the most. The high level of mineralization is occurred due to the presence of coal, iron ore and uranium mines. Great contribution to the salinity of water objects is made by the discharge of mine water, saline wastewater, water from cooling systems and brine infiltration of many slime storages (Buzylo et al., 2018; Liu et al., 2019). Unfortunately, modern methods of saline water treatment do not solve the problem, but only aggravate the situation in densely populated areas with welldeveloped industry (Gomelya et al., 2016).

The solution to this problem is the introduction of innovative complex water desalination technologies at the utilities and industrial enterprises (Kinnunen et al., 2017). It will helps to use water that has an increased mineralization, which will ensure a significant reduction of discharges of mineralized sewage and will lead to improvement of the quality of groundwater.

Membrane technologies have high efficiency and can be used at different stages of water treatment (Amaya-Vías et al., 2019), as well as together with other methods of purification (Kim et al., 2018).

In regions with a lack of fresh water, membrane technologies are widely used to desalinate highly mineralized waters (Haan et al. 2018).

Depending on the quality of the water and the requirements for the treated water, only membrane separation methods can be used for water treatment and wastewater treatment in a technologically grounded combination (Ambiado et al., 2017; Karakulski et al., 2006). 
The aim of this research work was to study the processes of desalination of mineralized waters, processing of formed concentrates, to develop the methods of utilization of sediments in the composition of building materials for the creation of innovative technologies of desalination of mineralized waters for ecologically safe water use systems.

\section{MATERIALS AND METHODS}

In this work, water desalination was studied using cartridges with low-pressure reverse osmosis membrane Filmtec TW30-1812-50 and the properties of the membrane is described in Table 1.

The model solution was used through experiments (hardness $-9.0 \mathrm{mg}$-eqv $/ \mathrm{dm}^{-3}$, alkalinity $-5.0 \mathrm{mg}$-eqv $/ \mathrm{dm}^{-3}, \mathrm{SO}_{4}^{2-}-13.0 \mathrm{mg}$-eqv $/ \mathrm{dm}^{-3}$, $\mathrm{Cl}^{-}-3.5 \mathrm{mg}$-eqv $/ \mathrm{dm}^{3}, \mathrm{pH}=8.9$ ). After filtering the solution through the weakly acid cationite Dowex MAC-3 in acid form, it had the following characteristics: hardness $-3.5 \mathrm{mg}$-eqv $/ \mathrm{dm}^{-3}$, acidity $-0.6 \mathrm{mg}$-eqv $/ \mathrm{dm}^{-3}, \mathrm{Cl}^{-}-3.5 \mathrm{mg}$-eqv $/ \mathrm{dm}^{-3}$, $\mathrm{SO}_{4}^{2-}-13.0 \mathrm{mg}$-eqv/dm ${ }^{-3}, \mathrm{pH}=3.5$.

For desalination of water, samples of $10 \mathrm{dm}^{3}$ were used. The degree of selection of permeate was changed from 10 to $90 \%$. The concentrations of chlorides, sulfates, hardness and alkalinity were determined in initial solutions and in permeates. The selectivity and productivity of the membrane were calculated (Gomelya et al., 2014).

Reagent water purification methods were used to soften and purify water model solution $\left(\mathrm{SO}_{4}^{2-} \quad-29.0 \mathrm{mg}\right.$-eqv $/ \mathrm{dm}^{-3}$, hardness $-21.5 \mathrm{mg}$-eqv $/ \mathrm{dm}^{-3}, \mathrm{Ca}^{2+}-1.8 \mathrm{mg}$-eqv $/ \mathrm{dm}^{-3}$,

Table 1. Properties of the reverse osmosis membrane Filmtec TW30-1812-50

\begin{tabular}{|l|c|}
\hline \multicolumn{1}{|c|}{ Parameter } & Value \\
\hline $\begin{array}{l}\text { Productivity, } \mathrm{dm}^{3} / \mathrm{day} \text { at a pressure of } 4-7 \text { bar } \\
\text { and temperature } 25{ }^{\circ} \mathrm{C}\end{array}$ & $225-395$ \\
\hline Stable salt removal, $\%$ & 98 \\
\hline Minimal salt removal, \% & 96 \\
\hline Maximum water supply, $\mathrm{dm}^{3} / \mathrm{min}$ & 7.6 \\
\hline Maximum operating pressure, bar & 21 \\
\hline Maximum operating temperature, ${ }^{\circ} \mathrm{C}$ & 45 \\
\hline Maximum colloidal index & 5 \\
\hline Ph range (long-term work) & $2-11$ \\
\hline Ph range (flushing up to $30 \mathrm{~min})$ & $1-13$ \\
\hline Maximum concentration of free chlorine, $\mathrm{mg} / \mathrm{dm}^{3}$ & $<0.1$ \\
\hline Size, mm & $295 \times 55$ \\
\hline
\end{tabular}

$\mathrm{Mg}^{2+}-19.7 \mathrm{mg}$-eqv/dm ${ }^{-3}, \mathrm{Cl}^{-}-2.7 \mathrm{mg}$-eqv $/ \mathrm{dm}^{-3}$, alkalinity $-19.0 \mathrm{mg}$-eqv $/ \mathrm{dm}^{-3}$ ) from sulfates by the treatment with lime and $2 / 3$ of hydroxychloride of aluminum with the formation and of calcium sulfoaluminate.

Water was treated with the calculated amount of lime and coagulant at stirring, the precipitate was separated in 3 hours, and filtrate was used to determine the content of sulfates, chlorides, alkalinity and $\mathrm{pH}$.

The degree of softening $(Z, \%)$ and the degree of removal of sulfates from water (A) were calculated by the formulas:

$$
Z, A=\left(1-\frac{H_{f}\left(C_{S O_{4}^{2-} f}\right)}{H_{i}\left(C_{S O_{4}^{2-i}}\right)}\right) \cdot 100
$$

where: $\mathrm{H}_{\mathrm{i}}, C_{\mathrm{SO}_{4}^{2-}}-$ initial hardness and concentration of sulfates, respectively;

$\mathrm{H}_{\mathrm{f}}, C_{\mathrm{SO}_{4 .}^{2-}}$-hardness and concentration of sulfates in purified water, respectively.

In order to prevent the sediment deposition on membranes in barometric methods, it is necessary to provide an effective stabilizing treatment of water. An effective lighting and discoloration of water is important at baromembrane water purification. Therefore, to reduce the load on the reverse osmosis membrane, increase the process productivity, increase the period of operation of reverse osmosis membranes, we proposed to conduct pre-treatment with the application of ultrafiltration membranes to purify water from suspended solids.

In the work, the effect of the mechanical water purification on the productivity and selectivity of the reverse osmosis membrane of low pressure Filmtec TW30-1812-50 was determined.

\section{RESULTS AND DISCUSSION}

The membrane Filmtec TW-30-1812-50 provides en effective water desalting at pressures up to $1 \mathrm{MPa}$ (in this case, $\mathrm{P}=0.3 \mathrm{MPa}$ ) with high process efficiency. Despite the fact that through a cassette with a reverse osmosis membrane only $10 \mathrm{dm}^{3}$ of model solution was passed, its prelighting significantly influenced the productivity of the membrane. During filtering an increase in membrane productivity on $12-20 \%$ is observed.

The efficiency of removal of chlorides, sulfates and ions of hardness from water slightly 
depends on the pre-purification of water. When desalting the model solution, the highest residual concentrations of chlorides were fixed in the permeate. The residual concentrations of sulfates and hardness ions were rather low. The content of ions in concentrates was determined by their initial concentration and the effectiveness of detention on the membrane.

In concentrates, the increase in concentrations of all cations and anions that were controlled in this process were observed. The highest concentrations correspond to hardness ions and to sulfates.

Since the efficiency of water purification from any ions depends not only on the residual concentrations of ions, but also on their initial concentration, then the efficiency of the water purification process from any ions is better to evaluate by the values of the membrane selectivity (Fig. 1).

During filtering, the Filmtec TW30-1812-50 membrane was characterized by the lowest selectivity of $89-95 \%$ in relation to chlorides; the selectivity towards sulfates and ions of hardness reached the values $98.8-99.7 \%$.

Thus, initial lighting of water leads to a decrease in water turbidity from 0.5 to $0.1 \mathrm{mg} / \mathrm{dm}^{3}$ and to increase in membrane productivity up to 1.2-2.0 times.

Another complicated problem of reverse-osmosis water purification is its preparation before membrane treatments. During treatment of water with membrane technologies, there is a problem of formation of deposits on the membranes, resulting in a decrease in the flow of filtrate and increased transmembrane pressure (Gryta et al., 2008). Therefore, along with effective lighting and discoloration, the problem of its stabilization to prevent sediment deposition on membranes is acute. The main reason for deposition of sediments is the deposition of calcium carbonate on the surface of the membrane. For this purpose corrosion inhibitors (Shmandiy et al., 2017; Gomelya et al., 2017) and water treatment on ion-exchange filters (Trokhymenko et al., 2017) can be used.

In the application of weakly acid cationite Dowex MAC-3 in the $\mathrm{H}^{+}$form there is a decrease in the alkalinity of water is observed (Gomelya et al., 2014). In this case, the alkalinity of water decreased to zero values, and the $\mathrm{pH}$ reached 3.9; and such water can not lead to the formation of carbonate deposits on the membrane.

In the work, the effect of stabilizing treatment of water on weakly acidic cake Dowex MAC-3 in the $\mathrm{H}^{+}$form on the efficiency of water desalination in a reverse osmosis membrane Filmtec TW 30-1812-50 was determined. The model solution after filtration through weakly acidic cake Dowex MAC-3 in acid form had the following characteristics: hardness $-3.5 \mathrm{mg}$-eqv $/ \mathrm{dm}^{-3}$, acidity $0 \mathrm{mg}$-eqv $/ \mathrm{dm}^{-3}, \mathrm{Cl}^{-}-3.5 \mathrm{mg}$-eqv $/ \mathrm{dm}^{-3}, \mathrm{SO}_{4}^{2-}-$ $13.0 \mathrm{mg}$-eqv $/ \mathrm{dm}^{-3}, \mathrm{pH}=3.9$.

The results of the evaluation of the productivity of the reverse osmosis membrane are shown in Figure 3.

As can be seen from Fig. 3, the productivity of the membrane at a working pressure of 0,30 $\mathrm{MPa}$ a little depends on the $\mathrm{pH}$ of the solution. Acidification of the solution with partial softening

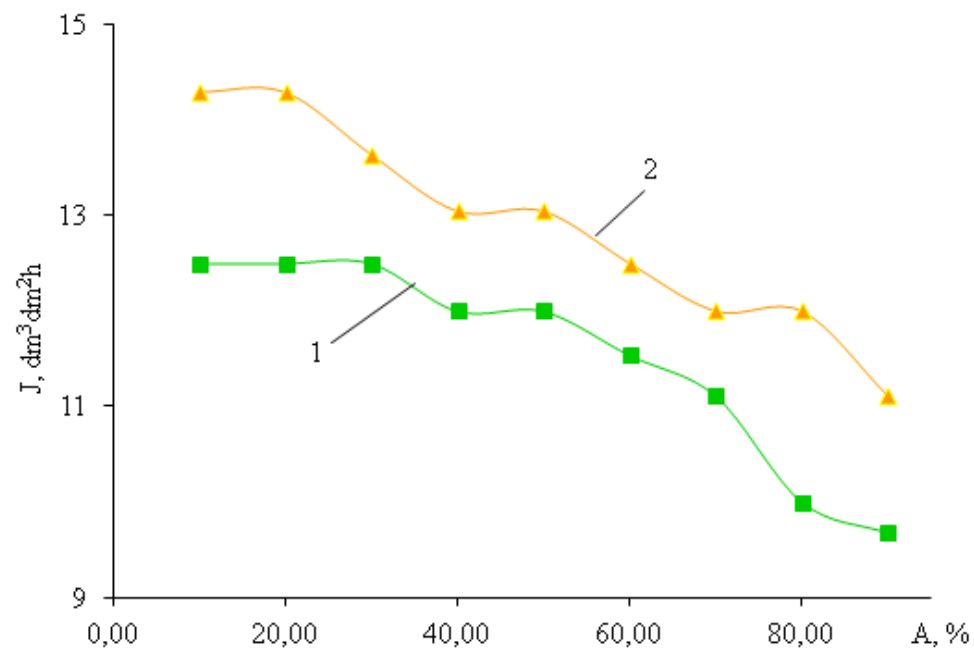

Figure 1. Dependence of the productivity of the reverse osmosis membrane Filmtec TW-30-1812-50 on the degree of selection of permeate during desalination of unfiltered (1) and filtered model solution (2) 
improves the productivity of the reverse osmosis membrane. It happens primarily due to the partial demineralization of the solution on the ion exchange filter and due to the absence of carbonate deposits on the membrane. During filtering of $10 \mathrm{dm}^{3}$ of water, there is no significant deposition of sediments on the membrane, so the effect of the $\mathrm{pH}$ of the medium on the performance is insignificant. At longer tests and larger volumes of water, the membrane's productivity after stabilization treatment of water will stay high during the time of use.

However, the selectivity of the membrane depends on the pre-treatment of water on cation exchanges. As can be seen from Fig. 4, as the $\mathrm{pH}$ of the medium was decreased, a slight increase in the selectivity of the membrane by sulfates and a significant decrease in its selectivity by chlorides was observed. Acidification of water leads to a decrease in the selectivity of the reverse osmosis membrane by chlorides by $10-30 \%$. The selectivity of the membrane practically does not depend on working pressure and stays high towards

a)

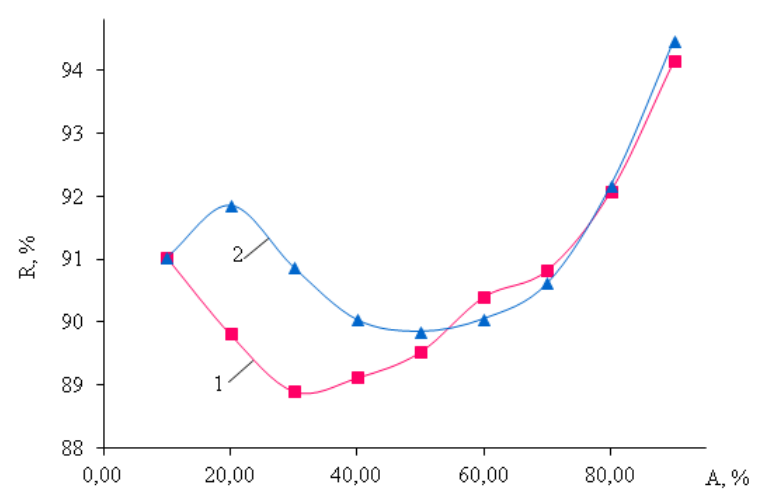

sulfates and ions of hardness (98-99\%), regardless of the $\mathrm{pH}$ and degree of selection of permeate.

The effectiveness of water purification can also be evaluate by the residual concentrations of chlorides, sulfates and hardness ions in permeates and their content in concentrate. One of the main problems of water purification is the recycling concentrate. It should be noted that in all cases concentrates, which formed, together with sulfates $\left(\approx 100.0 \mathrm{mg}\right.$-eqv $\left./ \mathrm{dm}^{-3}\right)$ also contain significant concentrations of ions of hardness (33.0-80.0 mg-eqv/ $/ \mathrm{dm}^{-3}$ ). For today, there are no economically feasible methods for the processing of concentrates, and their preservation in the sludge lead to deterioration of environmental situation. Therefore, it is necessary to develop the technological processes of their processing.

Among the promising methods, which is used to soften water solutions and to remove sulfates from them, the reagent method can be accented. The advantage of the method in comparison with ion exchange, baromembrane processes, distillation, electrodialysis is that it allows the remove

b)

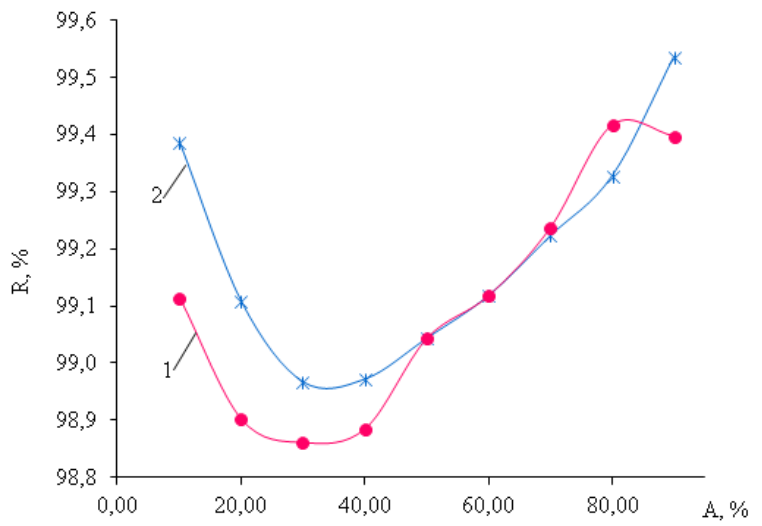

c)

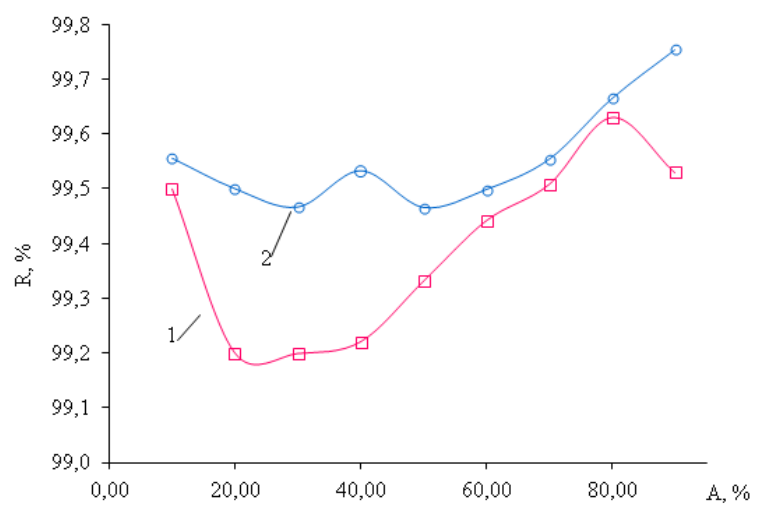

Figure 2. Dependence of the selectivity of the reverse osmosis membrane on chlorides (a), sulfates (b), ions of hardness (c) $(\mathrm{pH}=8.6$ (1), $\mathrm{pH}=3.9$ (2)) 


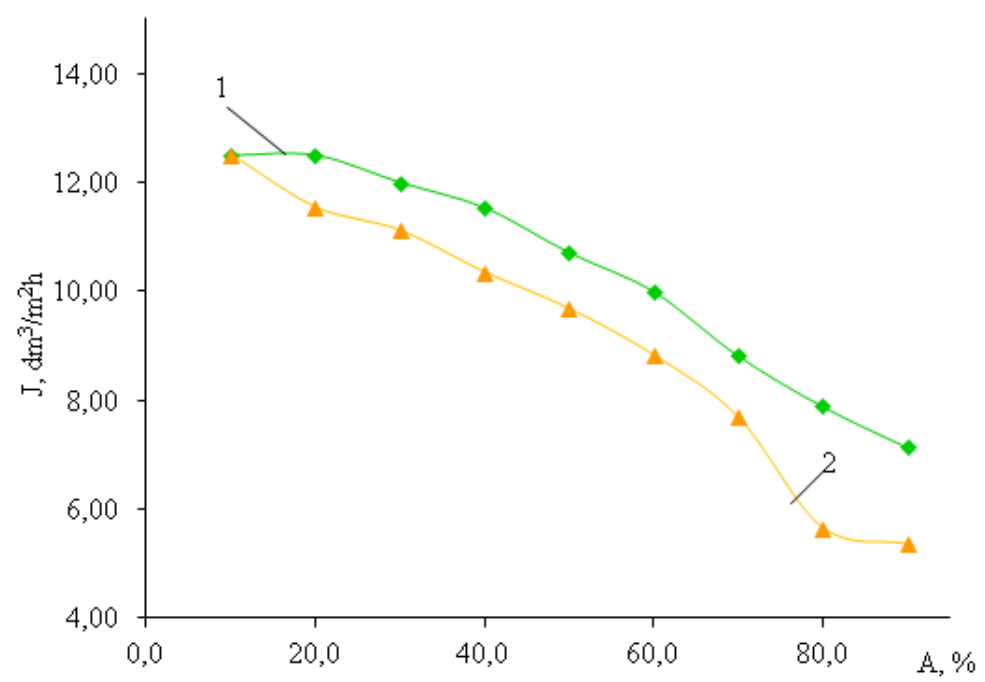

Figure 3. Dependence of the productivity of the reverse osmosis membrane on the degree of selection of permeate during desalting the filtrate after the cation filter Dowex MAC-3 in acid form $\mathrm{pH}=3.9$ (1) and model solution $\mathrm{pH}=8.6(2)$

a)

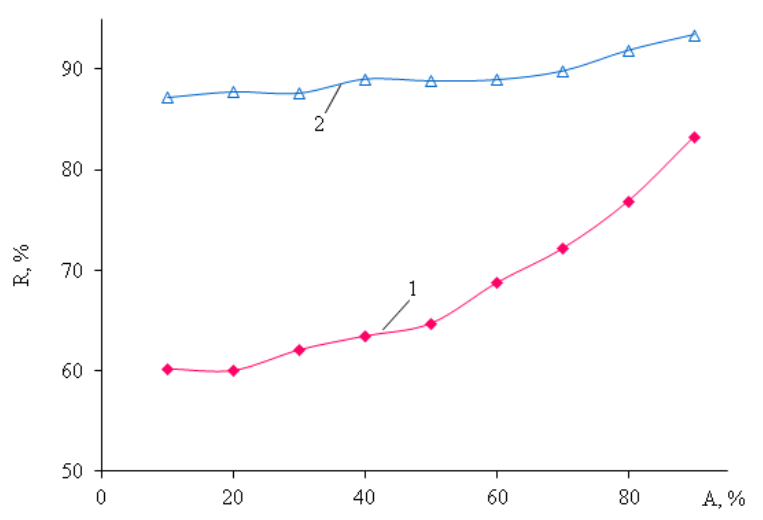

b)

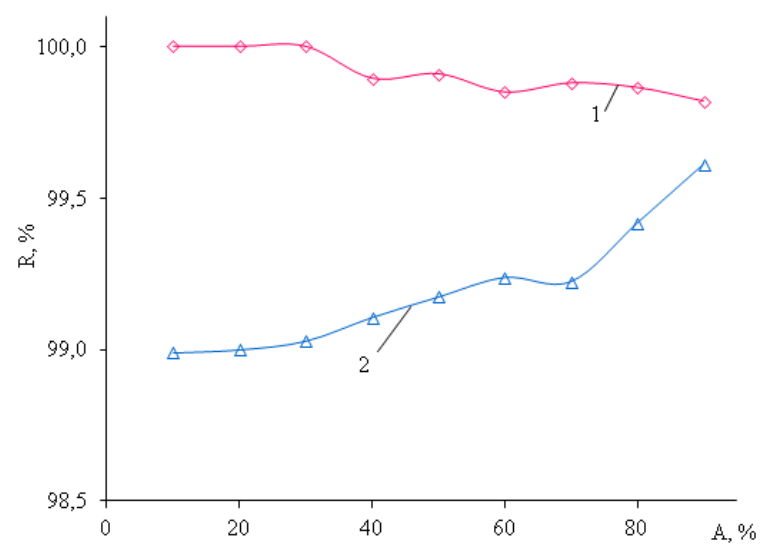

c)

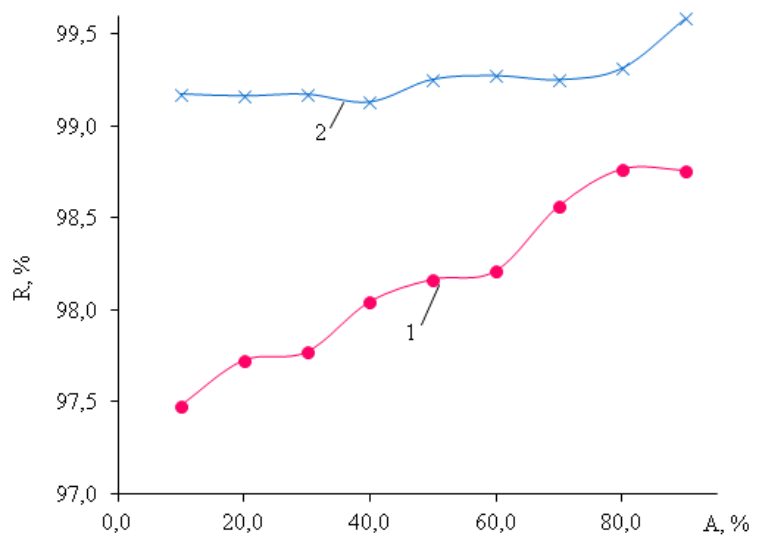

Figure 4. Dependence of the selectivity of the reverse osmosis membrane towards chlorides (a), sulfates (b), ions of hardness (c) on the degree of selection of permeate during desalination of solutions $(\mathrm{pH}=8.6(1), \mathrm{pH}=3.9$ (2)) 
sulfates from water in the form of a slightly soluble precipitate, while in other cases waste is formed in the form of salt solutions. In addition, the advantages of this method include the cheapness and simplicity of operation and equipment.

Iron (Parsons and Daniels, 1999) and aluminum coagulants (Prakash et al., 2003) are quite commonly spread. Processes of water treatment with lime and aluminum-contain coagulants are based on precipitation of calcium hydroxysulfonaluminate $\left(3 \mathrm{CaO} \cdot \mathrm{Al}_{2} \mathrm{O}_{3} \cdot 3 \mathrm{CaSO}_{4} \cdot 31 \mathrm{H}_{2} \mathrm{O}\right)$.

It is important to study the processes of demineralization of concentrates formed by reverse osmosis purification of mineralized waters, determine the conditions for effective softening of these solutions and purification from sulfates in the integrated treatment with lime and aluminum coagulants under the conditions of the least secondary contamination with chloride anions. When using aluminum coagulants, the consumption of reagents increases in proportion to the content of sulfates in water. An increase in the consumption of coagulants is undesirable because of their high cost, increased costs of water purification. Therefore, in this case, the solution was treated only with lime (Ostovar and Amiri, 2013). The residual sulfate content is reduced $\sim 20 \div 30 \mathrm{mg}$ eqv $/ \mathrm{dm}^{-3}$, hardness up to $\sim 10 \div 40 \mathrm{mg}$-eqv $/ \mathrm{dm}^{-3}$ (Gomelya et al., 2017; Gomelya et al., 2014).

Purification of concentrates was carried out by processing of samples with lime and aluminum coagulant during mixing. Efficiency of water purification from sulfates, as well as the effectiveness of its softening, depends on the consumption of lime and coagulant, and on their ratio. In order to purify the solution $\left(\mathrm{SO}_{4}^{2-}-29.0 \mathrm{mg}\right.$-eqv $/ \mathrm{dm}^{-3}$; hardness $-21.5 \mathrm{mg}$-eqv $/ \mathrm{dm}^{-3} ; \mathrm{Ca}^{2+}-1.8 \mathrm{mg}$-eqv $/ \mathrm{dm}^{-3}$; $\mathrm{Mg}^{2+}-19.7 \mathrm{mg}$-eqv $/ \mathrm{dm}^{-3} ; \mathrm{Cl}^{-}-2.7 \mathrm{mg}$-eqv $/ \mathrm{dm}^{-3}$; alkalinity $-190 \mathrm{mg}$-eqv/ $\mathrm{dm}^{-3}$ ) the lime and $2 / 3$ aluminum hydroxychloride was used (Table 2 ).

The application of these reagents is less than the stoichiometric amount is not feasible, since there is no effective softening of the solution and the degree of removal of sulfates is quite low. At a dose of coagulant of $4.8 \mathrm{mg}$-eqv $/ \mathrm{dm}^{-3}$, with an increase in the consumption of lime from 76.0 to $134.0 \mathrm{mg}$-eqv $/ \mathrm{dm}^{-3}$, there is an increase in the efficiency of purification from sulfates is observed. A similar situation occurs with an increase in the dose of $2 / 3$ aluminum hydroxychloride to $7.2 \mathrm{mg}$ eqv $/ \mathrm{dm}^{-3}$. At the same time, it is possible to reduce the concentration of sulfates to $2.7 \mathrm{mg}$-eqv $/ \mathrm{dm}^{-3}$. The residual alkalinity of water increases with the increase in the consumption of lime, but decreases with increasing dose of coagulant, which contributes to acidification of water.

Experimental data confirm that the precipitates formed as a result of water purification can be found to be used as part of cement as an extensible additive for cement and as an activator for curing slag-portland cement, as a substitute for natural gypsum stone and additive-accelerator in the composition of concrete (Trus et al., 2017).

\section{CONCLUSIONS}

1. The optimal parameters of membrane desalinization of solutions providing high water quality were determined in the work. The methods

Table 2. Dependence of the efficiency of softening and removal of sulfate from solution on the consumption of lime and $2 / 3$ of aluminum hydroxychloride

\begin{tabular}{|c|c|c|c|c|}
\hline $\begin{array}{l}\text { Dosage of } \mathrm{CaO} \text {. } \\
\mathrm{mg} \text {-eqv/dm } \mathrm{dm}^{-3}\end{array}$ & $\begin{array}{c}\text { Dosage of } 2 / 3 \text { of aluminum } \\
\text { hydroxychloride by } \mathrm{Al}_{2} \mathrm{O}_{3} \text {. mg-eqv/ } \\
\mathrm{dm}^{-3}\end{array}$ & A. $\%$ & Z. \% & $\begin{array}{l}\text { Alkalinity. mg-eqv/dm-3 } \\
\qquad\left(\mathrm{OH}^{-3} ; \text { total }\right)\end{array}$ \\
\hline 76.0 & 4.8 & 42.5 & 84.2 & $0.0 ; 9.5$ \\
\hline 87.0 & 4.8 & 58.5 & 89.8 & $0.0 ; 12.5$ \\
\hline 99.0 & 4.8 & 68.8 & 88.8 & $0.0 ; 17.0$ \\
\hline 110.0 & 4.8 & 65.5 & 45.6 & $4.8 ; 21.5$ \\
\hline 122.0 & 4.8 & 63.0 & 7.0 & $5.8 ; 34.0$ \\
\hline 134.0 & 4.8 & 69.5 & 0.0 & $11.0 ; 37.0$ \\
\hline 76.05 & 7.2 & 21.0 & 76.7 & $0.0 ; 9.0$ \\
\hline 87.65 & 7.2 & 63.2 & 72.1 & $0.0 ; 9.0$ \\
\hline 99.25 & 7.2 & 76.4 & 62.8 & $0.0 ; 8.0$ \\
\hline 110.85 & 7.2 & 86.0 & 48.8 & $0.0 ; 9.0$ \\
\hline 122.45 & 7.2 & 90.7 & 44.2 & $0.0 ; 9.0$ \\
\hline 134.05 & 7.2 & 88.2 & 30.2 & $0.0 ; 10.0$ \\
\hline
\end{tabular}


of stabilization treatment of water befor barometric desalination was developed to increase the efficiency of the productivity and the operation time of the membranes.

2. Methods of reagent processing of concentrates after barometric water purification for the creation of low-waste technologies for demineralization of water were developed.

3. It was shown that the precipitate formed after reagent softening of water using aluminumcooled coagulants can be used in the in the composition of building materials.

4. The developed technologies of integrated processing of mineralized waters allow ones to create low-waste technologies of desalting waters with complete processing of formed sediments.

\section{REFERENCES}

1. Buzylo V., Pavlychenko A., Savelieva T., Borysovska O. 2018. Ecological aspects of managing the stressed-deformed state of the mountain massif during the development of multiple coal layers. Paper presented at the E3S Web of Conferences, 60.

2. Liu D., Edraki M., Malekizadeh A., Schenk P. M., Berry L. 2019. Introducing the hydrate gel membrane technology for filtration of mine tailings. Minerals Engineering, 135, 1-8.

3. Gomelya M., Hrabitchenko V., Trohymennko A., Shablij T. 2016. Research into ion exchange softening of highly mineralized waters. Eastern-European Journal of Enterprise Technologies, 4(10-82), 4-9.

4. Kinnunen P., Kyllönen H., Kaartinen T., Mäkinen J., Heikkinen J., Miettinen V. 2018. Sulphate removal from mine water with chemical, biological and membrane technologies. Water Science and Technology, (1), 194-205.

5. Amaya-Vías D., Tataru L., Herce-Sesa B., LópezLópez J. A., López-Ramírez J. A. 2019. Metals removal from acid mine drainage (tinto river, $\mathrm{SW}$ spain) by water gap and air gap membrane distillation. Journal of Membrane Science, 582, 20-29.

6. Kim J. E., Phuntsho S., Chekli L., Choi J. Y., Shon H. K. 2018. Environmental and economic assessment of hybrid FO-RO/NF system with selected inorganic draw solutes for the treatment of mine impaired water. Desalination, 429, 96-104.

7. Haan T. Y., Shah M., Chun H. K., Mohammad A. W. 2018. A study on membrane technology for surface water treatment: Synthesis, characterization and performance test. Membrane Water Treatment, 9(2), 69-77.

8. Ambiado K., Bustos C., Schwarz A., Bórquez R.
2017. Membrane technology applied to acid mine drainage from copper mining. Water Science and Technology, 75(3), 705-715.

9. Gomelya M. D., Trus I. M., Radovenchyk I. V. 2014. Influence of stabilizing water treatment on weak acid cation exchange resin in acidic form on quality of mine water nanofiltration desalination. Naukovyi Visnyk Natsionalnoho Hirnychoho Universytetu, (5), 100-105.

10. Shmandiy V., Bezdeneznych L., Kharlamova O., Svjatenko A., Malovanyy M., Petrushka K. Polyuzhyn, I. 2017. Methods of salt content stabilization in circulating water supply systems. Chemistry and Chemical Technology, 11(2), 242-246.

11. Gomelya N. D., Shabliy T. A., Trohymenko A. G., Shuryberko M. M. 2017. New inhibitors of corrosion and depositions of sediments for water circulation systems. Journal of Water Chemistry and Technology, 39(2), 92-96.

12. Trokhymenko G., Gomelya M. 2017. Development of low waste technology of water purification from copper ions. Chemistry and Chemical Technology, 11(3), 372-377.

13. Gomelya N. D., Trus I. N., Nosacheva Y. V. 2014. Water purification of sulfates by liming when adding reagents containing aluminum. Journal of Water Chemistry and Technology, 36(2), 70-74.

14. Gomelya M., Trus I., Shabliy T. 2014. Application of aluminium coagulants for the removal of sulphate from mine water. Chemistry and Chemical Technology, 8(2), 197-203.

15. Trus I. M., Fleisher H. Y., Tokarchuk V. V., Gomelya M. D., Vorobyova V. I. 2017. Utilization of the residues obtained during the process of purification of mineral mine water as a component of binding materials. Voprosy Khimii i Khimicheskoi Tekhnologii, (6), 104-109.

16. Ostovar M., Amiri M. 2013. A novel eco-friendly technique for efficient control of lime water softening process. Water Environment Research, 85(12), 2285-2293.

17. Gryta M. 2008. Chemical pretreatment of feed water for membrane distillation. Chemical Papers, 62(6), 100-105.

18. Karakulski K., Gryta M., Sasim M. 2006. Production of process water using integrated membrane processes. Chemical Papers, 60(6), 416-421.

19. Prakash P., Sengupta A. K. 2003. Selective coagulant recovery from water treatment plant residuals using donnan membrane process. Environmental Science and Technology, 37(19), 4468-4474.

20. Parsons S.A., Daniels S.J. 1999. The use of recovered coagulants in wastewater treatment. Environmental Technology (United Kingdom), 20(9), 979-986. 